\title{
HORMONAL REGULATION OF STEROIDOGENIC ENZYME GENE EXPRESSION IN LEYDIG CELLS
}

\author{
A. H. Payne, * G. L. Youngalood, L. Sha, M. Burgos-Trinidad and S. H. Hammond \\ Departments of Obstetrics and Gynecology, Biological Chemistry and the Reproductive Sciences \\ Program, University of Michigan, Ann Arbor, MI 48109-0278, U.S.A.
}

\begin{abstract}
Summary-In normal mouse Leydig cells, steady state levels of mRNA of CYP11A, $3 \beta$-hydroxysteroid dehydrogenase $\Delta^{5}->\Delta^{4}$-isomerase ( $3 \beta$ HSD), and CYP17 are differentially regulated. There is high basal expression of $3 \beta$ HSD and CYP11A mRNA, while expression of CYP17 mRNA is absolutely dependent on cAMP stimulation. cAMP is required for maximal expression of all three enzymes. The expression of CYP11A in normal mouse Leydig cells is repressed by glucocorticoids. Glucocorticoids also repress both basal and cAMP-induced expression of $3 \beta$ HSD mRNA, but do not repress the synthesis or mRNA levels of CYP17. cAMP induction of $3 \beta$ HSD mRNA can be observed only when aminoglutethimide (AG), an inhibitor of cholesterol metabolism, is added to the Leydig cell cultures. The addition of AG also markedly increases cAMP induction of CYP17 mRNA levels. Addition of testosterone or the androgen agonist, mibolerone, to cAMP plus AG treated cultures reduced $3 \beta$ HSD and CYP17 mRNA levels to levels comparable to those observed when cells were treated with cAMP only. These data indicate that testosterone acting via the androgen receptor represses expression of both CYP17 and $3 \beta$ HSD. The role of protein synthesis in mediating the cAMP induction of $3 \beta \mathrm{HSD}$, CYP17 and CYP11A was examined. The addition of cycloheximide, an inhibitor of protein synthesis, to cAMP treated cultures for $24 \mathrm{~h}$ completely suppressed both constitutive and cAMP-induced $3 \beta$ HSD mRNA levels. Cycloheximide also repressed CAMP-induced levels of CYP17 to $12 \%$ of levels observed in the absence of cycloheximide. In sharp contrast, treatment for $24 \mathrm{~h}$ with cycloheximide did not suppress cAMP induction of CYPI1A mRNA, but reduced basal levels by approx. $50 \%$. These data indicate that newly synthesized protein(s) are required for CAMP induction of CYP17 and 3BHSD mRNA levels, but not for CYP11A mRNA.

A mouse $C y p 17$ genomic clone containing the entire coding region plus $10 \mathrm{~kb}$ of $5^{\prime}$ flanking region has been isolated. Fragments of $5^{\prime}$ flanking sequences were subcloned into vectors containing the CAT reporter gene and transfected into MA-10 Leydig cells. Transfected cells were treated with cAMP and expression was determined by measuring CAT activity. A cAMP responsive element was identified in a region between -245 and -346 bp relative to the transcription initiation site of Cyp 17. Cotransfection into MA-10 Leydig cells of constructs containing $4.5 \mathrm{~kb}$ of $C y p 175^{\prime}$ flanking sequences together with a mouse androgen receptor expression vector demonstrate a dose dependent repression of cAMP-induced $C y p 17$ transcription by the androgen receptor. Studies with the mouse Cyp Ila gene demonstrate that the $5^{\prime}$ flanking region of the gene contains sequences between 2.5 and $5 \mathrm{~kb}$ that are necessary for expression of mouse Cyp11a in Leydig cells but not in adrenal cells.
\end{abstract}

\section{INTRODUCTION}

Biosynthesis of testosterone from cholesterol in Leydig cells involves the action of four enzymes (Fig. 1). The initial rate-limiting step in this pathway is the conversion of the $\mathrm{C}_{27}$ steroid, cholesterol, to the $C_{21}$ steroid, pregnenolone, which is catalyzed by the cytochrome $P 450$ enzyme, cholesterol side-chain cleavage

Proceedings of the First International Symposium on $A$ Molecular View of Steroid Biosynthesis and Metabolism, Jerusalem, Israel, 14-17 October 1991.

*To whom correspondence should be addressed at: L'221 Women's Hospital, University of Michigan, Ann Arbor, MI 48109-0278.
(CYP11A). This enzyme is located in the inner mitochondrial membrane. Pregnenolone diffuses across the mitochondrial membrane and is further metabolized by enzymes associated with the smooth endoplasmic reticulum. In the mouse Leydig cell, pregnenolone is first converted to progesterone by the action of $3 \beta$-hydroxysteroid dehydrogenase $/ \Delta^{5}->\Delta^{4}$ isomerase ( $3 \beta$ HSD). The next reaction is catalyzed by the cytochrome $P 450$ enzyme, CYP17. CYP17 catalyzes two reactions, $17 \alpha$-hydroxylation of progesterone followed by cleavage of the $\mathrm{C}_{17-20}$ bond to yield the $\mathrm{C}_{19}$ steroid, androstenedione, the immediate precursor of testosterone. The final reaction in the bio- 
896

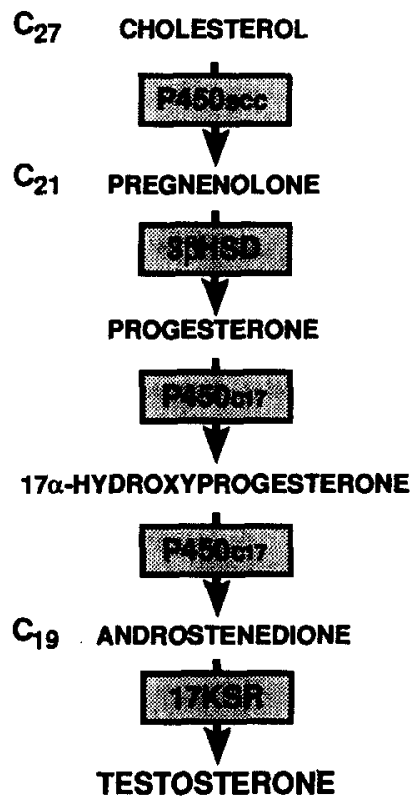

Fig. 1. Steroid biosynthetic pathway in Leydig cells. $P 450_{\mathrm{scc}}$ cytochrome $P 450$ cholesterol side-chain cleavage; $P 450 \mathrm{cl} 7$, cytochrome $P 450_{17 \alpha}$-hydroxylase/ $C_{17-20}$ lyase; $3 \beta \mathrm{HSD}, 3 \beta$ hydroxysteroid dehydrogenase $/ \Delta^{5}->\Delta^{4}$ isomerase; $17 \mathrm{KSR}$,

17 ketosteroid reductase.

synthesis of testosterone is the reduction of the 17 ketone of androstenedione by 17 ketosteroid reductase (17KSR).
This paper will focus on the regulation of expression of CYP11A, CYP17 and $3 \beta \mathrm{HSD}$ in mouse Leydig cell cultures by cyclic AMP (cAMP) and steroids as well as their tissue specific expression. Identification of a cAMPresponsive region in the mouse $C y p 17$ gene and repression of cAMP-induced expression of Cyp 17 by the mouse androgen receptor will be discussed as well as the identification of Leydig cell-specific sequences in the mouse Cyplla gene. A review by Waterman et al. [1] as part of this symposium issue summarizes unique cAMP-responsive sequences (CRS) in the bovine $C Y P 17$ and $C Y P 11 A$ genes and in the human $C Y P 21 B$ gene [1].

\section{REGULATION OF CYPIIA, CYP17 AND 3BHSD EXPRESSION IN MOUSE LEYDIG CELLS}

Earlier studies from our laboratory demonstrated that in mouse Leydig cell cultures cAMP is essential for de novo synthesis of CYP17, but not for CYP11A. In the absence of cAMP, de novo synthesis of CYP17 ceases, while CYP11A exhibits high basal synthesis [2]. We have also shown that steroid hormones negatively regulate de novo synthesis of CYP17 [3] and

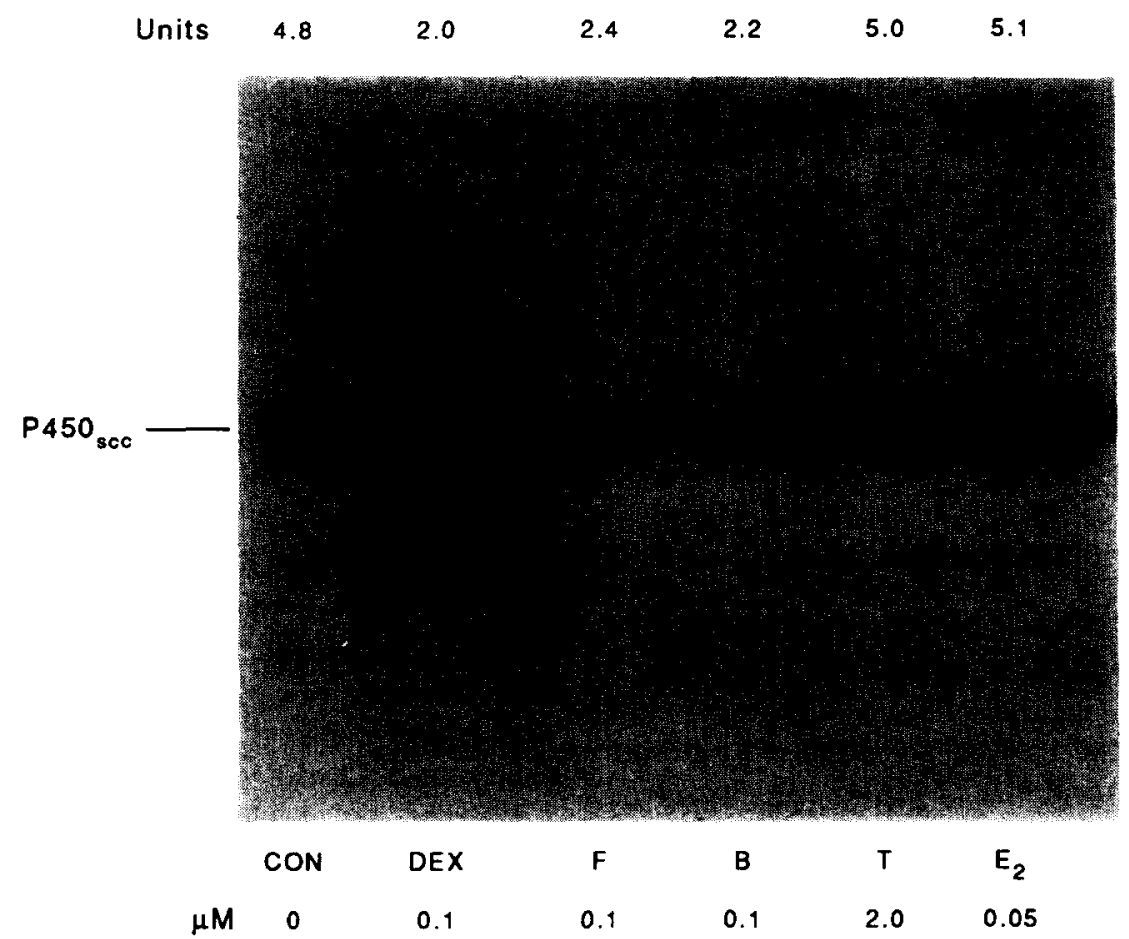

Fig. 2. Specificity of glucocorticoid-mediated repression of $P 450 \mathrm{sec}$ synthesis in mouse Leydig cells. Leydig cells were incubated for 4 days before treatment for $24 \mathrm{~h}$ with $0.1 \mu \mathrm{M}$ dexamethasone (DEX), $0.1 \mu \mathrm{M}$ cortisol (F), $0.1 \mu \mathrm{M}$ corticosterone (B), $2 \mu \mathrm{M}$ testosterone (T), or $0.05 \mu \mathrm{M}$ estradiol ( $\mathrm{E}_{2}$ ). Cultures were radiolabeled, and $P 450 \mathrm{sec}$ was immunoisolated from $30 \mu \mathrm{g}$ lysate. ${ }^{35} \mathrm{~S}$-labeled $P 450 \mathrm{scc}$ was quantitated by densitometry, and relative units are expressed above each lane. CON, control. From Hales and Payne [4] 


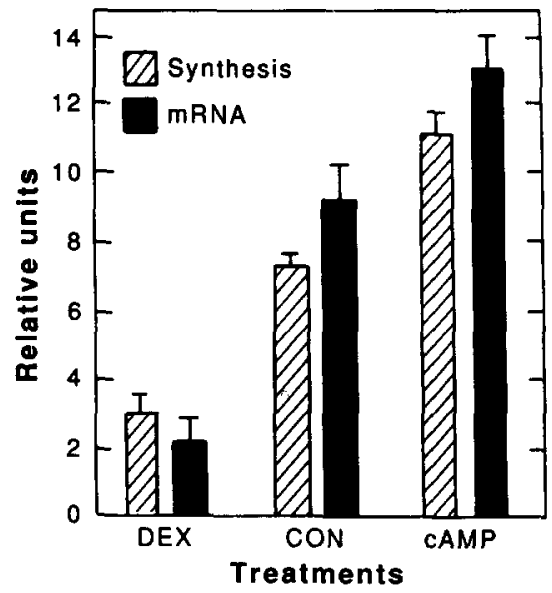

Fig. 3. Effect of cAMP and dexamethasone on $P 450 \mathrm{scc}$ synthesis and mRNA levels in mouse Leydig cells. Cultures were treated for 6 days before the initiation of treatment for $24 \mathrm{~h}$ with $0.1 \mu \mathrm{M}$ dexamethasone (Dex) or $50 \mu \mathrm{M} \mathrm{8-Br}$ cAMP (cAMP) and P450scc synthesis and mRNA levels were quantitated in parallel in three separate experiments. $P 450$ sec de novo synthesis was measured as described in Fig. 2 and mRNA was quantitated by dot blot hybridization. CON, nontreated controls. From Hales and Payne [4]

CYP11A [4] in normal mouse Leydig cells. The repression is specific for a particular steroid hormone and for the enzyme. Glucocorticoids repress both basal and cAMP-stimulated CYP11A protein synthesis and mRNA levels as shown in Figs 2 and 3 [4], while testosterone represses cAMP-induced synthesis of CYP17 [2]. The repression by these steroids can be pre- vented by the appropriate steroid antagonist. RU486 prevents the repression caused by dexamethasone [4] while hydroxyflutamide prevents the repression caused by testosterone [3]. These findings indicate that the repression caused by these steroid hormones is mediated via their respective steroid receptors. Estradiol has no effect on the synthesis of CYP11A (Fig. 2) or CYP17 $[3,4]$. In contrast to our finding in normal Leydig cells, the glucocorticoid, dexamethasone, stimulates both de novo synthesis and steady state levels of CYP11A mRNA in MA-10 tumor Leydig cells [5]. The stimulatory effect of dexamethasone in MA-10 cells is additive to the stimulatory effect of cAMP [5]. Although glucocorticoids are not produced in Leydig cells, glucocorticoid receptors have been demonstrated in interstitial cells of the rat testis [6]. Increased production of glucocorticoids in pathologic conditions of the adrenal cortex, such as Cushing's syndrome can be associated with reproductive dysfunction, including decreased circulating testosterone [7]. The studies from our laboratory have identified two sites in the biosynthetic pathway from cholesterol to testosterone, CYP11A and $3 \beta \mathrm{HSD}$, where increased circulating concentrations of glucocorticoids could act to decrease testicular testosterone production $[4,8]$.

In more recent studies we have investigated cAMP induction and steroid repression of
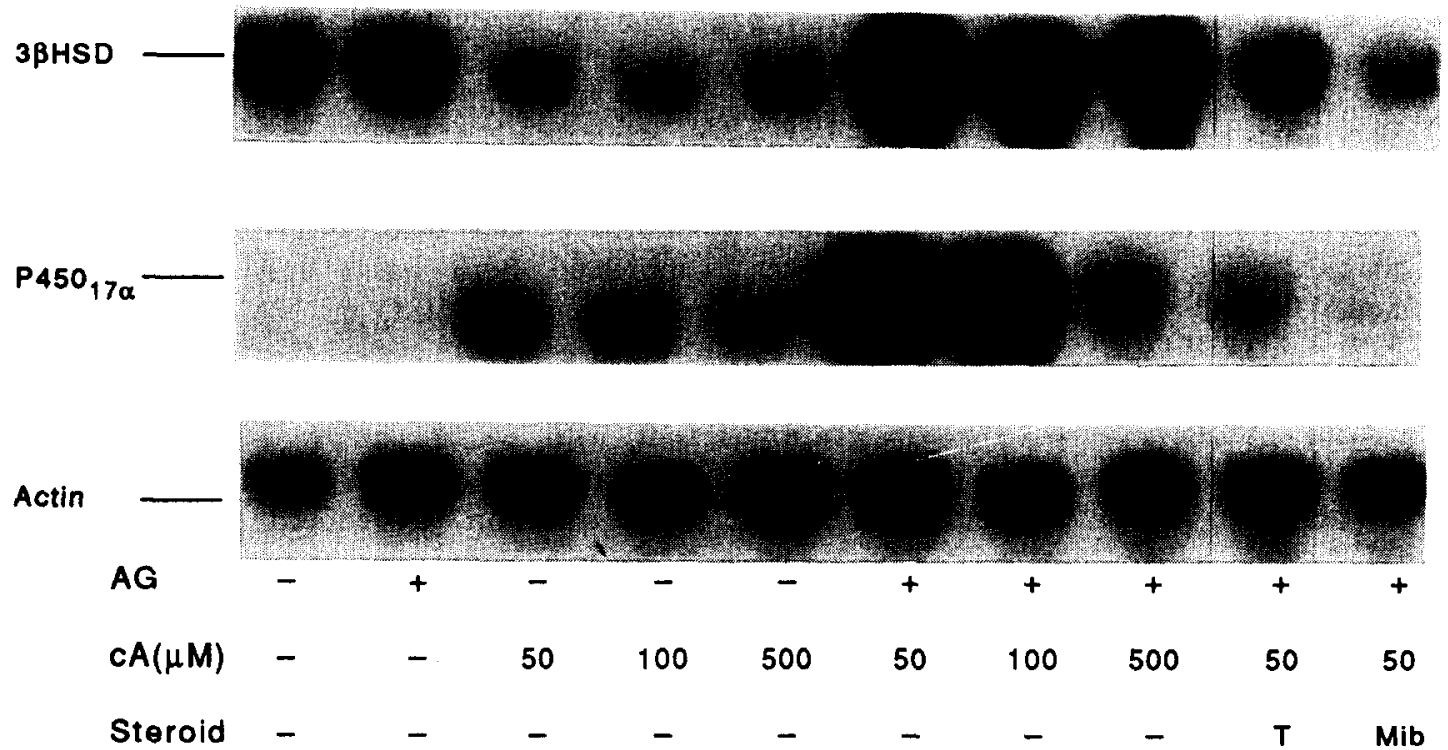

Fig. 4. Effect of cAMP and androgens on $3 \beta$ HSD and CYP17 $\left(P 450_{17 \alpha}\right)$ mRNA levels. Mouse Leydig cells were incubated for 6 days before treatment for $24 \mathrm{~h}$ with increasing concentrations of cAMP (cA) in the presence or absence of $0.5 \mathrm{mM}$ aminoglutethimide (AG) and where indicated $2 \mu \mathrm{M}$ mibolerone (Mib) or $2 \mu \mathrm{M}$ testosterone (T). Total cytoplasmic RNA was isolated and $7 \mu \mathrm{g}$ were subjected to Northern analysis and hybridized sequentially with $3 \beta$ HSD, Cyp 17 and $\beta$-actin DNA probes. From Payne and Sha [8]. 

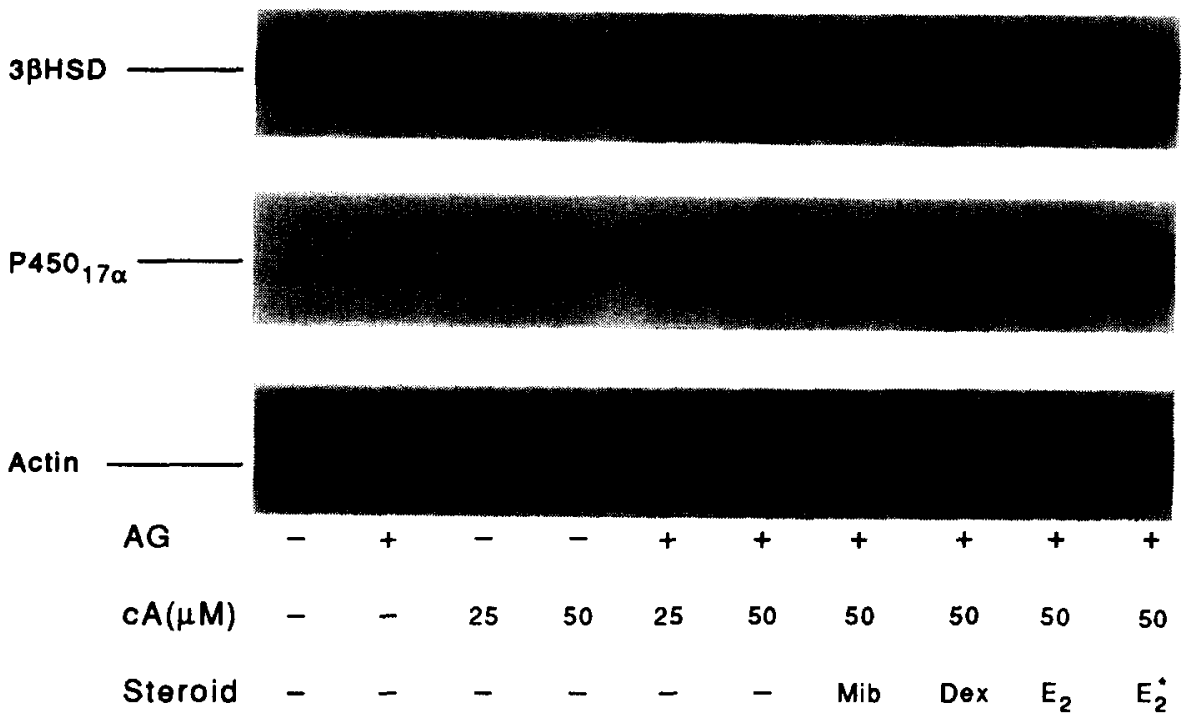

Fig. 5. Effects of mibolerone, dexamethasone, and estradiol on $3 \beta$ HSD and CYP17 $\left(P 450_{17 \alpha}\right)$ mRNA levels. Mouse Leydig cells were incubated and treated as described in Fig. 4. Mibolerone (Mib; $2 \mu \mathrm{M}$ ), dexamethasone (Dex; $100 \mathrm{nM}$ ), estradiol $\left(\mathrm{E}_{2} ; 100 \mathrm{nM}\right)$, and $\left(\mathrm{E}_{2}^{*} ; 1 \mu \mathrm{M}\right)$ were added to cAMP- plus aminoglutethimide (AG)-treated cultures where indicated. Total cytoplasmic RNA was isolated and $7 \mu \mathrm{g}$ were subjected to Northern analysis and hybridized, as described in Fig. 4. From Payne and Sha [8].

CYP17 and 3 $\beta$ HSD mRNA levels in mouse Leydig cell cultures. Purified mouse Leydig cells are incubated in a serum-free medium containing $0.1 \%$ bovine serum albumin and $500 \mu \mathrm{g} / \mathrm{ml}$ insulin. Cultures are maintained for 6 days prior to treatment. Figure 4 illustrates that in the absence of treatment with cAMP, CYP17 mRNA levels are undetectable while $3 \beta$ HSD mRNA is expressed at high basal levels, similar to what is found with CYP11A mRNA (Fig. 3). Treatment of Leydig cell cultures for $24 \mathrm{~h}$ with increasing concentrations of cAMP (50-500 $\mu \mathrm{M})$ markedly decreases the levels of $3 \beta \mathrm{HSD}$ mRNA relative to that of untreated control cultures while CYP17 mRNA levels are induced [8]. The addition of aminoglutethimide, an inhibitor of cholesterol metabolism, together with cAMP results in marked increases in both CYP17 and $3 \beta$ HSD mRNA levels relative to untreated control cultures or to cultures treated only with cAMP (Fig. 4). This observation suggests that testosterone, which is produced in high amounts during treatment of normal mouse Leydig cell cultures with cAMP, represses the cAMP induction of both $3 \beta$ HSD and CYP17 mRNA's [8]. To test this hypothesis, exogenous testosterone or the androgen agonist, mibolerone, was added to cultures treated with cAMP plus aminoglutethimide. Data presented in Figs 4 and 5 demonstrate that testosterone markedly represses the cAMP induction of $3 \beta \mathrm{HSD}$ and CYP17 mRNA and that this effect of testosterone can be mimicked by the androgen agonist, mibolerone. The repression of CYP17 and $3 \beta$ HSD mRNA by testosterone is not a general effect of steroids or a general effect of testosterone on all steroidogenic enzymes. Estradiol does not repress CYP17 or $3 \beta$ HSD expression (Fig. 5 and Ref. [8]). Dexamethasone represses basal (Fig. 6) and cAMP-induced levels of $3 \beta$ HSD mRNA, but not of CYP17 mRNA (Fig. 5 and Ref. [8]).

The requirement for newly synthesized proteins in mediating cAMP induction of CYP17 and $3 \beta$ HSD differs from that of CYP11A (Fig. 6). Inhibition of protein synthesis for $24 \mathrm{~h}$ by the addition of cycloheximide to Leydig cell cultures $30 \mathrm{~min}$ before treatment completely suppressed both basal and cAMP-induced expression of $3 \beta \mathrm{HSD}$ mRNA. Cycloheximide also markedly suppressed the cAMP induction of CYP17 mRNA. In contrast, the same treatment with cycloheximide did not suppress cAMP induction of CYP11A mRNA, however, basal expression was reduced.

The role of protein synthesis and the time required for maximal cAMP induction of CYP17 and CYP11A mRNA was investigated in greater detail [5]. Determination of cAMPstimulated mRNA levels of CYP17 and CYP11A in the same Leydig cell cultures at 6, 12 and $24 \mathrm{~h}$ following treatment with cAMP in the presence or absence of cycloheximide resulted in the following observations: (1) cAMP induction of CYP11A mRNA is slow, 
with the greatest increase over basal levels occurring between 12 and $24 \mathrm{~h}$; (2) cAMPinduced increases in CYP11A mRNA at 12 and $24 \mathrm{~h}$ were not prevented by the addition of cycloheximide, while basal expression was reduced approx. 50\%; (3) the temporal pattern of cAMP induction of CYP17 was very similar to that of CYP11A, a marked increase in CYP17 mRNA levels was observed between 12 and $24 \mathrm{~h}$; (4) inhibition of protein synthesis markedly suppressed cAMP induction of CYP17 at all time intervals examined [8]. These data indicate that newly synthesized proteins are required for cAMP induction of CYP17 and 3 $\beta$ HSD mRNA levels, but not for CYP11A mRNA. Furthermore, maximal induction by cAMP of CYP17 and CYP11A mRNA takes several hours. This type of response is characteristic of genes whose induction by cAMP is mediated by newly synthesized proteins [9]. The results with cycloheximide, however, indicate that cAMPinduced increases in CYP11A mRNA do not require newly synthesized proteins. These findings indicate that cAMP-induced increases in these two P450 mRNA's in normal mouse Leydig cells occur by a different mechanism(s).
The role of protein synthesis in mediating cAMP induction of CYP17 and CYP11A has been studied in a variety of steroidogenic cells from different species. The results appear to be dependent on the cell type and experimental conditions. John et al. [10] and Zuber et al. [11] reported that in cultures of bovine adrenocortical cells cycloheximide prevented the cAMP induction of CYP11A and CYP17 mRNA. These results indicate that in bovine adrenal cells newly synthesized proteins are required for the cAMP induction of both CYP17 and CYP11A mRNA. More recently, however, the same laboratory studied chimeric reporter gene constructs containing the $5^{\prime}$ cAMP responsive sequences of either bovine CYP11A or CYP 17 transiently transfected into bovine adrenocortical cells or Y-1 mouse adrenal tumor cells $[12,13]$. Inhibition of protein synthesis by cycloheximide did not reduce cAMP-induced expression of these transiently transfected reporter genes containing either CYPIIA or $C Y P 17$ sequences. The reason for the discrepancy of the effect of cycloheximide on the expression of endogenous bovine genes and that of reporter genes is not obvious at this time. Other reports on the role of newly synthesized proteins in mediating cAMP induction of
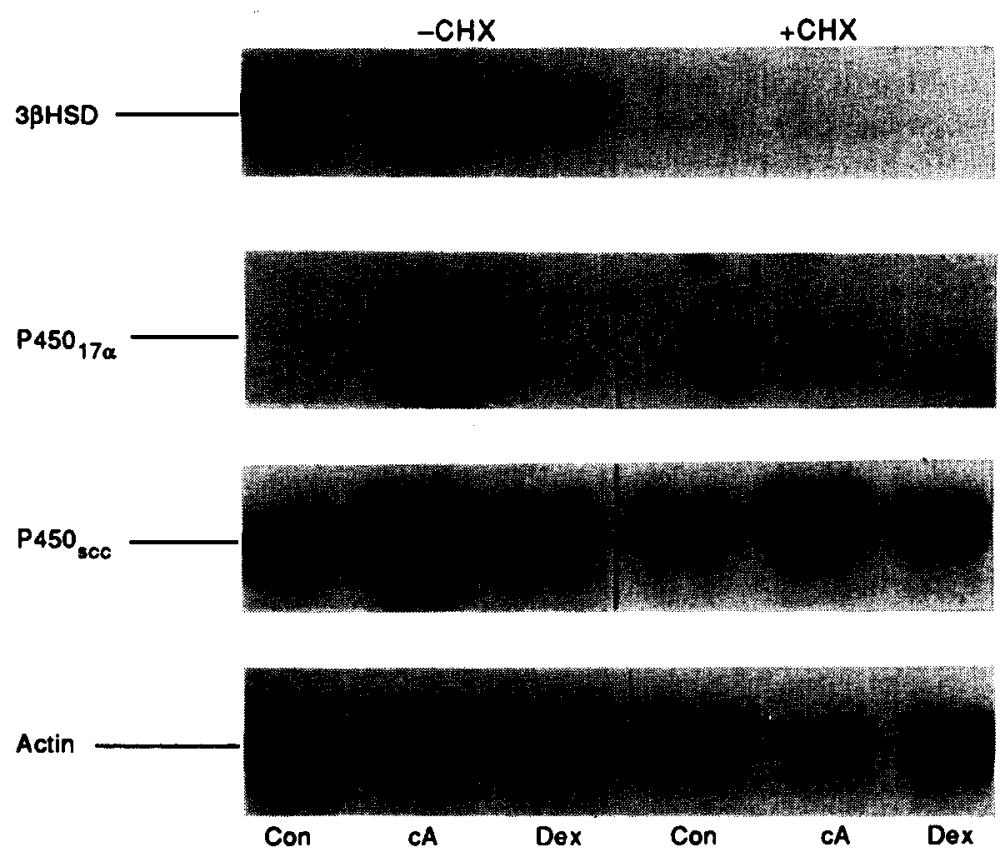

Fig. 6. Effect of inhibition of protein synthesis on the expression of $3 \beta \mathrm{HSD}, \mathrm{CYP} 17\left(P 450_{17 \alpha}\right)$ and CYPI1A $(P 450 \mathrm{scc})$ mRNA. Leydig cells were incubated and treated as described in Fig. 4. Cycloheximide (CHX; $10 \mu \mathrm{g} / \mathrm{ml}$ ) was added $30 \mathrm{~min}$ before addition of $50 \mu \mathrm{M}$ cAMP (cA) or $100 \mathrm{nM}$ dexamethasone (Dex). CHX was added to untreated control cultures (Con) at the same time as it was added to the other cultures. After $24 \mathrm{~h}$, total RNA was isolated and subjected to Northern analysis and hybridized sequentially with $3 \beta$ HSD, Cyp 17, Cyp $11 a$ and $\beta$-actin cDNA probes. From Payne and Sha [8]. 

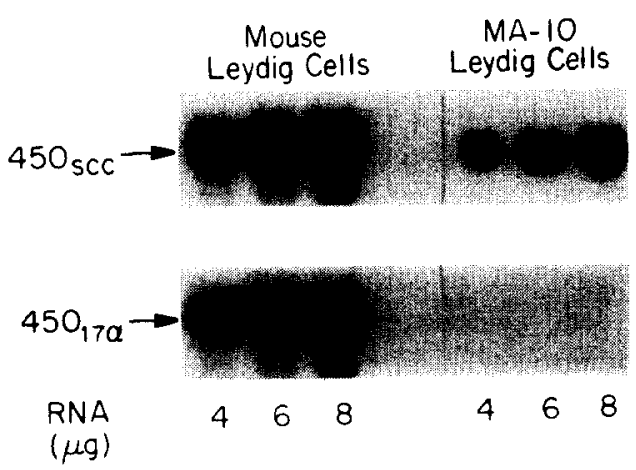

Fig. 7. MA-10 Leydig tumor cells do not express CYP17 mRNA. Total cytoplasmic RNA was extracted from Metrizamide gradient-purified Leydig cells or from MA-10 Leydig tumor cells and increasing amounts of RNA, as indicated, were subjected to Northern analysis and hybridized sequentially with Cyp $11 \mathrm{a}(P 450 \mathrm{scc})$ and $C y p 17$ $\left(P 450_{17 a}\right)$ DNA probes.

CYP11A mRNA do not show a consistent pattern. Cycloheximide inhibition of cAMPstimulated increases in CYP11A mRNA was reported in the transformed human trophoblastic cell line JEG-3 [14], but was not observed for CYP11A in cultures of human granulosa cells $[15]$. We previously reported that cAMP- and dexamethasone-induced increases in CYP11A mRNA are blocked by cycloheximide in MA-10 tumor Leydig cells in contrast to normal mouse Leydig cells [16]. No effect of cycloheximide was observed on basal levels of CYP11A mRNA. In contrast to our results in MA-10 cells, Mellon and Vaise [17] reported that cycloheximide does not inhibit cAMP-stimulated increases in CYP11A mRNA in this Leydig cell line, but decreases basal CYP11A mRNA levels. The differences in the two studies are probably due to differences in the time cells were exposed to cycloheximide, since in normal Leydig cells we observed an effect of cycloheximide on cAMP induction of CYP11A mRNA at $6 \mathrm{~h}$ but not after 12 or $24 \mathrm{~h}$ of treatment [8]. The role of newly synthesized protein mediators in cAMP-induced transcription of the genes encoding CYP11A and CYP17 requires further investigation.

\section{ISOLATION AND CHARACTERIZATION OF MOUSE Cyp17 AND IDENTIFICATION OF A CAMP-RESPONSIVE REGION}

To investigate the regulation of expression of Cyp 17 gene at the transcriptional level, we have isolated the mouse structural gene encoding CYP17. Two genomic clones containing the entire coding region and approximately 10 kilobases $(\mathrm{kb})$ of $5^{\prime}$ flanking sequences of $C y p 17$ were isolated and characterized [18]. To identify sequences involved in the cAMP regulation of mouse $C y p 17$ and to investigate further the mechanism by which cAMP induces transcription of Cyp 17, fragments $5^{\prime}$ of the coding region were subcloned into vectors containing the chloramphenicol acetyl transferase (CAT) reporter gene [18]. Constructs containing different lengths of $5^{\prime}$ upstream sequences up to $4.5 \mathrm{~kb}$ were transiently transfected into MA-10 tumor Leydig cells and treated with cAMP. MA-10 tumor Leydig cells do not express endogenous CYP17 mRNA as shown in Fig. 7, and thus produce progesterone rather than testosterone when stimulated with human chorionic gonadotropin [19] or with cAMP [5]. cAMP response of the constructs was determined by measuring CAT activity (amount of chloramphenicol acetylated with $\left[{ }^{3} \mathrm{H}\right]$ acetate) in the cell extracts. Figure 8 illustrates that treatment of transfected MA-10 cells with cAMP showed the greatest increase in Cyp 17CAT activity in the construct containing $1.1 \mathrm{~kb}$ of $5^{\prime}$ flanking sequence. No increase in CAT

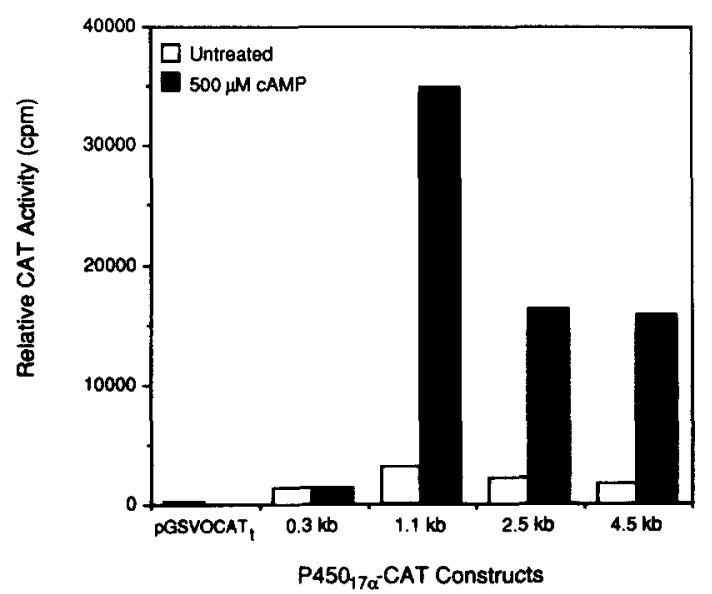

Fig. 8. Localization of $C y p I 7\left(P 450_{17 x}\right) 5^{\prime}$ regulatory regions responsible for $C A M P$ induction. Plasmids were constructed by subcloning different size kilobase (kb) fragments $5^{\prime}$ of the Cyp 17 coding region into the multiple cloning site of a promoterless plasmid, pGSVOCAT $_{t}$, pGSVOCAT, $_{t}$ was constructed by inserting the chloramphenicol acetyltransferase (CAT) reporter gene into $p G e m 7 Z f+$. A terminator fragment ( $\mathrm{t}$ ) containing an SV40 poly-A addition signal was inserted into the pGem-CAT upstream of the multiple cloning region. MA-10 Leydig tumor cells were transfected transiently with the indicated constructs ( $5 \mu \mathrm{g}$ DNA). After $24 \mathrm{~h}$ cells were treated for $12 \mathrm{~h}$ in the absence (open bars) or presence (closed bars) of $500 \mu \mathrm{M}$ 8-Br-cAMP. CAT activity was measured in cell extracts by measuring the amount of $\left[{ }^{3} \mathrm{H}\right]$ acetylated chloramphenicol produced during $2 \mathrm{~h}$. All cultures were cotransfected with $5 \mu \mathrm{g}$ of SV $2 \beta$-gal and CAT activity is expressed relative to $\beta$-galactosidase activity $(\beta$-gal) [8] 


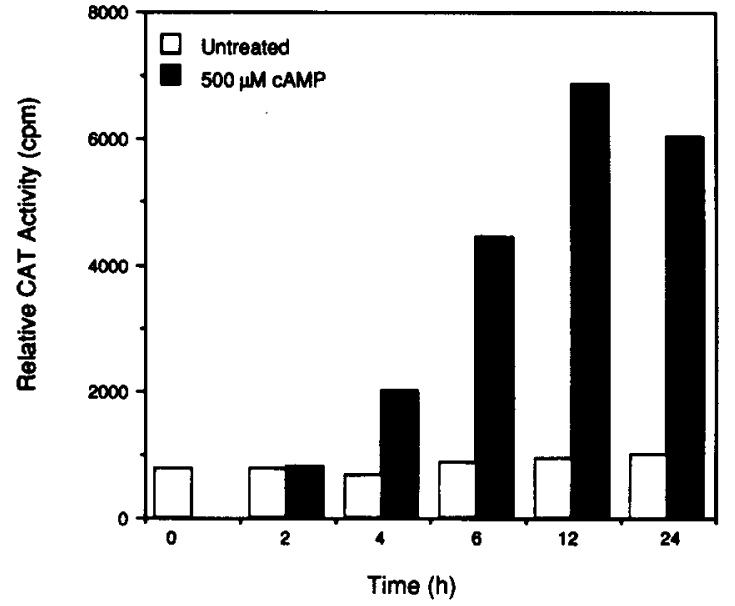

Fig. 9. Time course of cAMP induction of Cyp17-CAT expression in MA-10 cells. Cells were transfected transiently with the $1.1 \mathrm{~kb}$ Cyp 17-CAT construct as described in Fig. 8. Cells were treated in the absence (open bars) or presence of $500 \mu \mathrm{M}$ cAMP (closed bars) for the time indicated.

activity was detected in the construct containing $0.3 \mathrm{~kb}$ of $5^{\prime}$ flanking sequences, and cAMPinduced expression of the constructs containing 2.5 and $4.5 \mathrm{~kb}$ of the $5^{\prime}$ flanking region was less than that observed with the $1.1 \mathrm{~kb}$ construct. These data demonstrate that the cAMPresponsive region is between 0.3 and $1.1 \mathrm{~kb}$. Expression in the absence of cAMP treatment of the MA-10 cells results in very low expression of the Cyp17-CAT constructs similar to ex- pression of the endogenous Cyp 17 in normal Leydig cells. The observation that MA-10 cells express the transfected Cyp 17-CAT constructs when stimulated with cAMP, even though they do not express endogenous Cyp 17, demonstrates that these cells contain the transacting factors essential for expression of this gene.

To establish the concentration of cAMP necessary for maximal induction of expression of the Cyp17-CAT construct containing $1.1 \mathrm{~kb}$ of 5 ' flanking region, MA-10 cells transfected with this construct were treated with increasing concentrations of 8-Br-cAMP $(0-1000 \mu \mathrm{M})$. Maximal expression of Cyp 17-CAT was observed at a concentration of $500 \mu \mathrm{M}$ cAMP. No further increase was seen in cells treated with $1000 \mu \mathrm{M}$ cAMP. The time course of induction of the $1.1 \mathrm{~kb}$ Cyp 17-CAT construct by $500 \mu \mathrm{M}$ cAMP is shown in Fig. 9. No increase in CAT expression was seen after $2 \mathrm{~h}$ of treatment. After $4 \mathrm{~h}$ of treatment with cAMP Cyp 17-CAT expression was increased by approx. 3-fold with a maximal increase of 7.5-fold seen after $12 \mathrm{~h}$. The relatively long time required for the initial and the maximal increase in cAMP-induced Cyp17-CAT expression is similar to the long time required for maximal cAMP induction of the endogenous gene in Leydig cells [8] and is consistent with the

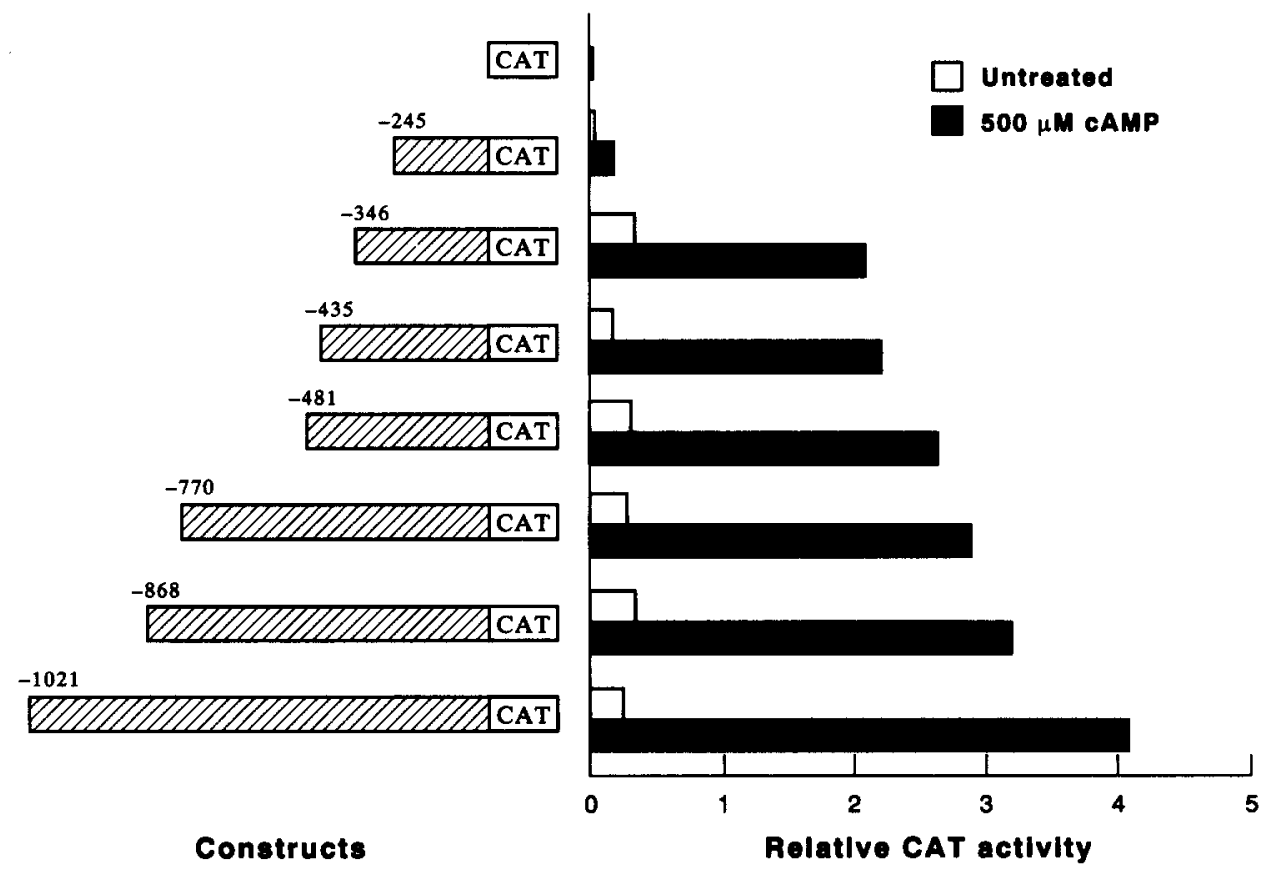

Fig. 10. Identification of sequences responsible for cAMP induction of the $5^{\prime}$ flanking region of the mouse Cyp 17 gene. Cells were transfected with the Cyp17-CAT construct indicated on the left-hand side of the figure and treated for $12 \mathrm{~h}$ in the absence (open bars) or the presence (closed bars) of $500 \mu \mathrm{M} \mathrm{cAMP}$ as described in Fig. 8. 


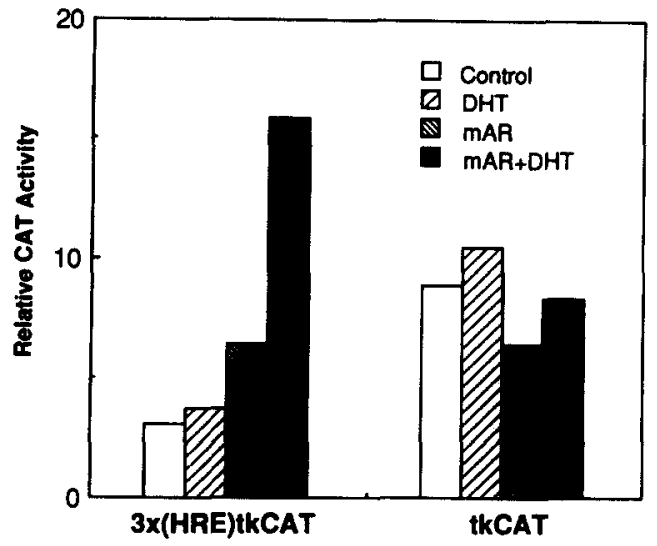

Fig. 11. Transfection of the mAR into MA-10 cells. MA-10 cells were transfected by the calcium phosphate precipitation method with either the $3 \times$ (HRE) $t k$ CAT reporter plasmid $(5 \mu \mathrm{g})$ containing a trimer of a hormone-response element for the Slp gene fused to the herpes simplex virus thymidine kinase $(k k)$ promoter and the bacterial CAT gene, or with the $t k \mathrm{CAT}$ reporter plasmid $(5 \mu \mathrm{g})$ lacking the HREs, in the presence or absence of the mAR expression plasmid $(4 \mu \mathrm{g})$. After $24 \mathrm{~h}$ of incubation cells were untreated, or treated with $2 \mu \mathrm{M}$ DHT for $12 \mathrm{~h}$ as indicated. The CAT activity was determined in cell extracts by measuring the amount of $\left[{ }^{3} \mathrm{H}\right]$ acetylated chloramphenicol produced during $2 \mathrm{~h}$. All cultures were cotransfected with $3 \mu \mathrm{g}$ of SV $2 \beta$-gal and results are expressed relative to $\beta$-galactosidase activity $(\beta$-gal).

hypothesis that the mouse Cyp 17 gene belongs to the class of cAMP-responsive genes that require a newly synthesized protein(s) and that cAMP-induced increases are probably not mediated by the ubiquitous CRE-binding protein (CREB) [9].

To further define sequences essential for cAMP induction, additional deletions of the $1.1 \mathrm{~kb} 5^{\prime}$ flanking construct were made. The results of those studies are shown in Fig. 10. Very low expression is seen in the construct containing $-245 \mathrm{bp}$, with a marked increase seen in the construct containing up to $-346 \mathrm{bp}$. This construct also shows a small increase in basal expression. There appears to be a further increase in cAMP-induced expression in the constructs containing between -435 and $-1021 \mathrm{bp}$. These data indicate that the cAMPresponsive region is between -245 and -346 with possibly additional enhancement of the cAMP-induced expression by sequences found between -435 and $-1021 \mathrm{bp}$.

When the sequence of the mouse Cyp 17 cAMP-responsive region $(-245 /-346)$ is aligned to the cAMP-responsive sequences of the human [20] and bovine [21] genes, no apparent homology was observed among these three CYP17 cAMP-responsive regions [18]. Previous studies by Brentano et al. [22] on human
CYP17-CAT constructs transfected into MA10 Leydig cells showed very low expression of the CAT reporter gene and a minimal cAMP response. These findings with the human $\mathrm{CYP} 17$ constructs are in sharp contrast to the data we observed with the mouse Cyp17-CAT constructs transfected into MA-10 Leydig cells, suggesting that there are species-specific and perhaps tissue-specific factors necessary for cAMP-induced expression of the Cyp 17 and CYP17 genes.

\section{REPRESSION OF CAMP-INDUCED EXPRESSION OF Cyp17 BY THE MOUSE ANDROGEN RECEPTOR}

Previous studies from our laboratory demonstrated that testosterone or the androgen agonist mibolerone repressed cAMP induction of CYP17 protein synthesis [3] and mRNA levels [8] in normal mouse Leydig cells. The repression of cAMP-induced increases by testosterone could be prevented by the androgen antagonist, hydroxyflutamide [3]. These data indicated that endogenous testosterone produced during cAMP induction of CYP17 negatively regulates the rate of CYP17 protein synthesis and mRNA levels by an androgen receptor-mediated mechanism $[3,8]$. To investigate whether this repression of cAMP-induced CYP17 protein synthesis and mRNA levels by an androgen receptor-mediated mechanism occurred at the level of transcription, experiments were carried out using the Cyp 17-CAT construct containing $4.5 \mathrm{~kb}$ of $5^{\prime}$ flanking

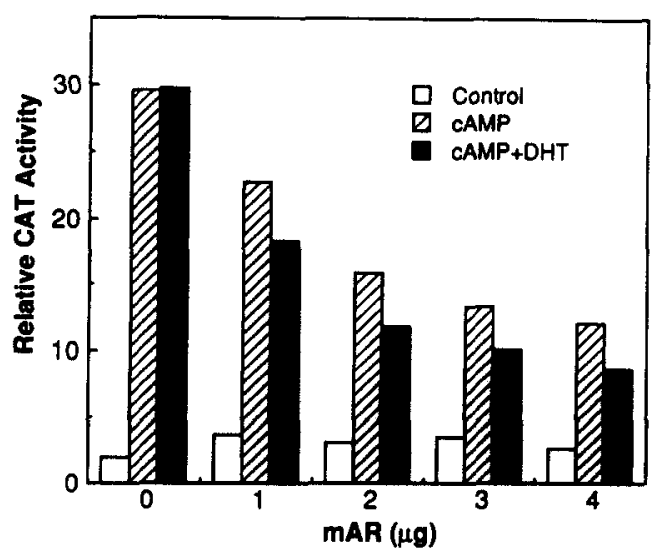

Fig. 12. Effect of $m A R$ on cAMP-induced expression of Cyp 17. MA-10 cells were cotransfected with the $4.5 \mathrm{~kb}$ Cyp 17-CAT construct $(5 \mu \mathrm{g})$ prepared as described in Fig. 7, SV2 $\beta$-gal $(5 \mu \mathrm{g})$, and increasing amounts of the mAR expression plasmid as indicated. Cells were treated as described in Fig. 11 with $500 \mu \mathrm{M} 8$-Br-cAMP or cAMP plus $2 \mu \mathrm{M}$ DHT. 
region. The initial experiment examined whether the MA-10 tumor Leydig cells contain endogenous androgen receptors.

To test for the presence of endogenous androgen receptor, MA-10 cells were transiently transfected with a construct containing 3 copies of androgen-responsive sequences [ $3 \times$ (HRE)] isolated from the androgen-responsive sexlimited protein (Slp) gene upstream of the thymidine kinase $(t k)$ promoter fused to the CAT reporter gene [3 $\times($ HRE $) t k$ CAT] [23]. This construct has been shown to interact with the mouse androgen receptor and its expression is dependent on androgen. Treatment of MA-10 cells transfected with the $3 \times(\mathrm{HRE}) t k \mathrm{CAT}$ plasmid with the androgen dihydrotestosterone (DHT) did not increase CAT activity suggesting that MA-10 cells do not contain endogenous androgen receptor (Fig. 11). We therefore cotransfected the MA-10 cells with a mouse androgen receptor (mAR) expression vector [24]. Cotransfection of the $3 \times$ (HRE) $t k$ CAT with the mAR expression vector followed $18 \mathrm{~h}$ later by treatment with DHT for $12 \mathrm{~h}$ resulted in a 3- to 4-fold increase in CAT activity (Fig. 11). DHT treatment of cells cotransfected with the $\mathrm{mAR}$ and with the $t k \mathrm{CAT}$ reporter gene lacking the $3 \times(\mathrm{HRE})$ did not result in an increase in CAT activity.

To examine the effect of androgens on cAMPinduced expression of Cyp 17-CAT, MA-10 cells were cotransfected with the $4.5 \mathrm{~kb}$ Cyp 17-CAT construct $(5 \mu \mathrm{g})$ and with increasing amounts of the mAR $(0-4 \mu \mathrm{g})$ and treated for $12 \mathrm{~h}$ with cAMP or CAMP plus DHT. Figure 12 illustrates that increasing amounts of $\mathrm{mAR}$ caused a dosedependent repression of cAMP-induced Cyp 17 CAT expression in the absence of DHT. The addition of DHT resulted only in a small further decrease in CAT activity of $\sim 25 \%$. No effect of DHT was observed in the absence of cotransfected mAR. The observed dose-dependent decrease in cAMP-induction of Cyp 17-CAT expression with increasing amounts of $\mathrm{mAR}$ alone and the small additional decrease observed with the addition of DHT suggest that cAMP has the capacity to activate the androgen receptor. To test this hypothesis, the $3 \times$ (HRE) $t k$ CAT construct was cotransfected with $4 \mu \mathrm{g}$ mAR into MA-10 cells and cells were treated with $500 \mu \mathrm{M}$ cAMP, $2 \mu \mathrm{M}$ DHT or cAMP plus DHT. Treatment with cAMP resulted in a similar increase in the $3 \times$ (HRE) tkCAT expression as was observed when cells were treated with DHT only. Treat- ment with cAMP plus DHT resulted in essentially the same amount of induction as with either compound alone (Fig. 13). These data suggest that CAMP as well as DHT can activate the mAR. Furthermore, these data suggest that activation of the androgen receptor involves phosphorylation of the receptor. This suggestion is supported by a report by van Laar et al. [25] that steroid hormone-induced phosphorylation of the human androgen receptor was accompanied by transformation of the receptor protein to a tight nuclear binding form. Thus, our observations in the present study and the report by van Laar et al. are consistent with the proposal that activation of the androgen receptor involves phosphorylation. Denner et al. [26] reported similar findings of cAMP or progesterone activation of the chicken progesterone receptor as we observed with the mAR. These authors showed that progesterone receptor-mediated transcription of a target gene, in transiently transfected CV1 cells, was increased by treatment of cells with 8-Br-cAMP in the absence of the steroid ligand, progesterone. This finding indicates that the chicken progesterone receptor as well as the mAR can be activated by cAMP as well as by their respective steroid ligands. Future studies should determine whether CAMP activation of steroid receptors is an alternate mechanism for activating all steroid receptors or whether cAMP activation is specific for certain steroid receptors.

Data presented in this section indicate that the androgen receptor-mediated repression of CYP17 protein synthesis and mRNA levels observed in mouse Leydig cells reflects an inter-

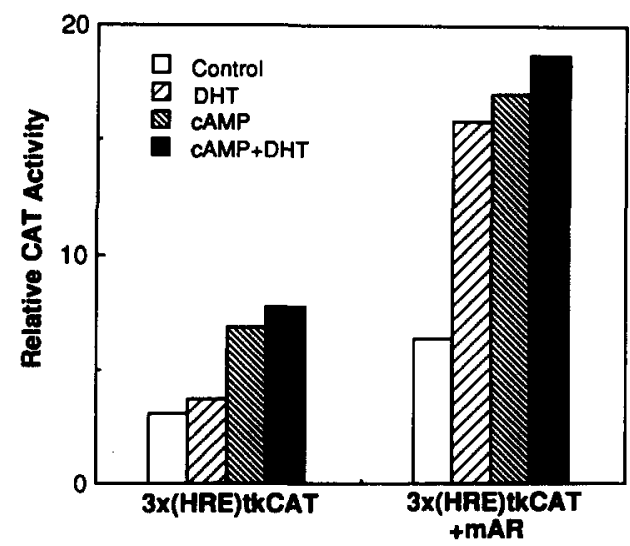

Fig. 13. Activation of the androgen receptor by cAMP or DHT. MA-10 cells were cotransfected with the $3 \times$ (HRE) $t k$ CAT plasmid $(5 \mu \mathrm{g})$, the mAR $(4 \mu \mathrm{g})$ and SV $2 \beta$-gal $(3 \mu \mathrm{g})$ as described in Fig. 11. Cells were untreated or treated for $12 \mathrm{~h}$ with $2 \mu \mathrm{M}$ DHT, $500 \mu \mathrm{M}$ cAMP or cAMP plus DHT. 
action of the androgen receptor with DNA sequences located in the $5^{\prime}$ flanking region of the Cyp 17 gene.

\section{LEYDIG CELL SPECIFIC SEQUENCES FOR THE EXPRESSION OF MOUSE Cyp11a}

In a recent study on the analysis of the promoter region of the gene encoding mouse Cyp 11a, it was found that constructs containing $1500 \mathrm{bp}$ of $5^{\prime}$ flanking region, when transfected into mouse $Y-1$ adrenocortical cells, exhibited high levels of expression of a growth hormone reporter gene [27]. In contrast, the same construct showed very low expression in mouse MA-10 Leydig cells. To examine whether additional sequences are necessary for the expression of the Cyplla gene in Leydig cells, a ${ }^{32}$ P-labeled probe containing +150 to -1300 of the mouse Cyp1la gene (a gift from Dr Keith Parker) was used to screen an EMBL-3 mouse genomic library. A clone containing $\sim 13,000 \mathrm{bp}$ of $5^{\prime}$ flanking sequences plus $4000 \mathrm{bp}$ of the structural gene was characterized by restriction mapping and partial sequencing. Constructs containing different lengths of $5^{\prime}$ flanking sequences up to approx. $-8000 \mathrm{bp}$ were subcloned into vectors containing the CAT reporter gene and transiently transfected into MA-10 Leydig cells or Y-1 adrenocortical cells. Expression with the different constructs in each cell type was determined by measuring the CAT activity in the cell extracts. The results of this study are shown in Fig. 14. Basal expression of Cyp1la in Y-1 adrenocortical cells was greatest in the construct containing $-1200 \mathrm{bp}$. No additional increase in expression of Cyp $11 a$ was observed in $\mathrm{Y}-1$ adrenocortical cells with constructs up to $-5000 \mathrm{bp}$ of $5^{\prime}$ flanking sequences relative to a minimal promoter containing $-198 \mathrm{bp}$. In Leydig cells, very little expression of the Cyp 1la gene constructs was observed in plasmids containing up to $2500 \mathrm{bp}$ $5^{\prime}$ of the coding region. As shown in Fig. 14, a marked increase in expression in MA-10 Leydig cells was observed with a construct that contained $5000 \mathrm{bp} 5^{\prime}$ of the coding region. This observation suggests that sequences between -2500 and $-5000 \mathrm{bp}$ are essential for expression of Cyp 11a in Leydig cells. To examine this finding further, a plasmid was constructed in which sequences between $-198 \mathrm{bp}$ and -2500 bp were deleted. The data presented in Fig. 14 demonstrate that sequences between 2.5 and $5.0 \mathrm{~kb} \mathrm{5}$ of the coding region of Cyp $11 \mathrm{a}$ are essential for expression in Leydig cells but not in adrenal cells. Further deletion studies are underway to localize more precisely the Leydig cell-specific sequences.

Previous studies from this laboratory indicated that Cyp $11 a$ expression was regulated differently in Leydig cells and adrenal glands of

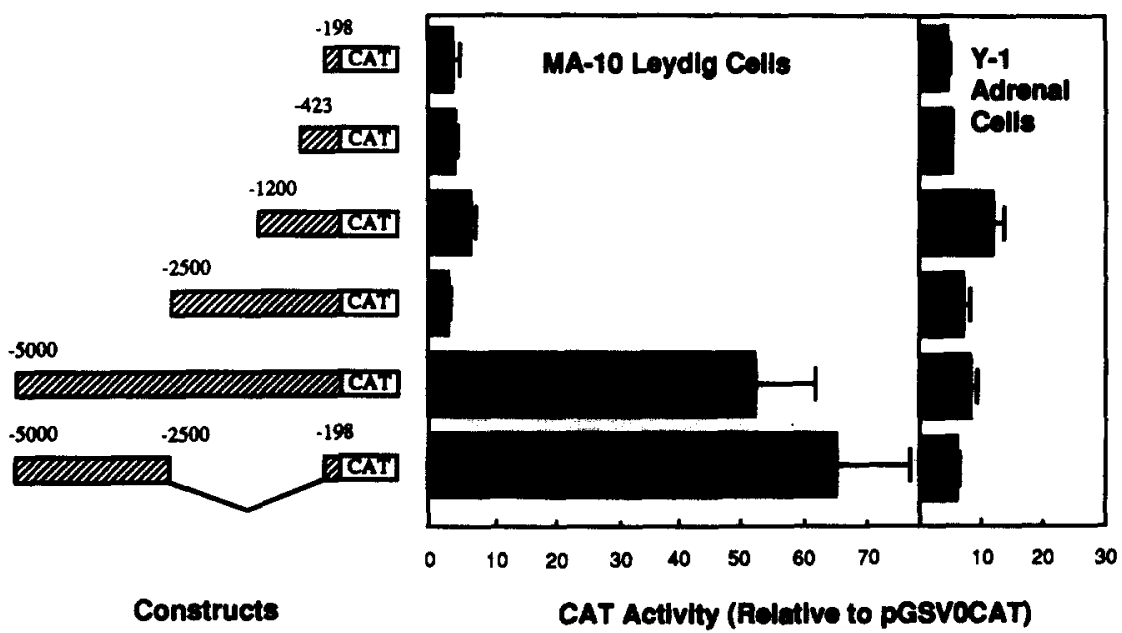

Fig. 14. Identification of Leydig cell specific sequences for the expression of mouse Cyp Ila. Different size fragments $5^{\prime}$ of the Cyp Ila coding region were subcloned into the multiple cloning site of a promoterless plasmid (pGSVOCAT) as described in Fig. 8, except that pGSVOCAT does not contain the terminator fragment. The Cyplla constructs are shown on the left hand side of the figure. $10 \mu \mathrm{g}$ of the indicated plasmid and $5 \mu \mathrm{g}$ of SV2 $\beta$-gal were transfected transiently into MA-10 Leydig tumor cells or $\mathrm{Y}-1$ adrenocortical tumor cells. Cells were harvested $36 \mathrm{~h}$ following transfection and CAT activity was determined in cell extracts by measuring the amount of $\left[{ }^{3} \mathrm{H}\right]$ acetylated chloramphenicol produced during $2 \mathrm{~h}$ for MA-10 cells or $1 \mathrm{~h}$ for $\mathrm{Y}-1$ cells. Transfection efficiency was corrected for $\beta$-galactosidase activity. CAT activity is expressed relative to the promoterless pGSVOCAT plasmid. 
the mouse [28]. Using inbred strains of mice, we identified two strains of mice, RF/J and SWR/J, whose Leydig cells exhibited a high amount of immunoreactive CYP11A and two strains, $\mathrm{DBA} / 2 \mathrm{~J}$ and $\mathrm{C} 3 \mathrm{H} / \mathrm{HeJ}$, whose Leydig cells exhibited a low amount of CYP11A. The pattern of expression of CYP11A in adrenal glands from the same mice was different from that in Leydig cells. The amount of CYP11A was highest in the adrenal glands of $\mathrm{C} 3 \mathrm{H} / \mathrm{HeJ}$ and lowest in SWR/J[28]. These findings suggested that tissue specific factors in adrenal and/or Leydig cells influence the expression of this enzyme. In a subsequent study, in which we investigated the relationship of the Cyp 1Ia structural gene and the amount of CYP11A protein, we demonstrated that quantitative differences in mouse Leydig cell CYP11A protein are determined either by Cyplla or by a closely linked locus [29]. No evidence could be found that this locus determined quantitative differences in mouse adrenal CYP11A (C. J. Nolan and A. H. Payne, unpublished data). These studies provide additional evidence that expression of CYP11A in Leydig and adrenal cells is regulated by different mechanisms.

\section{CONCLUSIONS}

This chapter reviews the complexity of the regulation of expression of the enzymes involved in testosterone production in Leydig cells. The three major enzymes studied, CYP11A, CYP17 and 3 $\beta$ HSD are differentially regulated. Maximal levels of mRNA for the three enzymes requires cAMP. There is high basal expression of both CYP11A and $3 \beta \mathrm{HSD}$ mRNA, while expression of CYP17 mRNA is absolutely dependent on chronic stimulation by cAMP. Endogenously produced testosterone in normal mouse Leydig cells acting via the androgen receptor negatively regulates expression of cAMP-induced CYP17 as well as $3 \beta$ HSD mRNA, while glucocorticoids acting via the glucocorticoid receptor repress CYP11A and $3 \beta$ HSD mRNA levels. The mechanism by which CAMP increases expression of the three enzymes in normal mouse Leydig cells is different. Newly synthesized proteins are essential for cAMP induction of CYP17 and $3 \beta$ HSD mRNA, but not for CYP11A mRNA. In the absence of protein synthesis for a $24 \mathrm{~h}$ period, basal levels of $3 \beta \mathrm{HSD}$ mRNA are completely repressed while basal levels of CYP11A mRNA are reduced by $50 \%$ indicating that rapidly turning over proteins are required for basal expression of $3 \beta \mathrm{HSD}$ and CYP11A mRNA.

Data are presented identifying the cAMPresponsive region in the $5^{\prime}$ flanking sequences of mouse Cyp 17. Constructs containing different length fragments of the Cyp $175^{\prime}$ flanking region fused to the CAT reporter gene were transfected into MA-10 tumor Leydig cells, and sequences between -245 and -346 were identified as the cAMP-responsive region. We demonstrate that $12 \mathrm{~h}$ are required for cAMP to maximally increase Cyp 17-CAT expression and that no increase in expression is observed at $2 \mathrm{~h}$ with only a small increase at $4 \mathrm{~h}$. This observation is consistent with the results observed in normal mouse Leydig cells that cAMP induction of CYP17 mRNA requires newly synthesized proteins. Furthermore, we demonstrate that repression by the androgen receptor of cAMP induction of $\mathrm{Cyp} 17$ occurs at the level of transcription. In addition, data are presented that indicate that the mAR can be activated by cAMP in the absence of the androgen ligand. This observation provides evidence for a novel mechanism of steroid receptor activation which may lead to new theories about the transformation of steroid receptors from an inactive form to an active DNA-binding form.

Evidence is presented for the presence of specific sequences in the $5^{\prime}$ flanking region of the Cyp Ila structural gene that are required for Leydig cell expression. These data indicate that there are tissue-specific factors that are necessary for expression of CYP11A in Leydig cells and in adrenal glands.

Acknowledgements - The authors gratefully acknowledge Dr Tamara Greco, Paul Bain and Trent Clarke for their input in the preparation of this manuscript. These studies were supported by National Institutes of Health Grants HD-08358 and HD-17916 to A. H. Payne. S. H. Hammond was supported by a NICHD training Grant HD-07048.

\section{REFERENCES}

1. Waterman M. R., Kagawa N., Zanger U. M., Momoi K., Lund J. and Simpson E. R.: Comparison of cAMPresponsive DNA sequences and their binding proteins associated with expression of the bovine CYP17 and CYP11A and human CYP21B genes. J. Steroid Biochem. Molec. Biol. 43 (1992) 931-935.

2. Anakwe O. O. and Payne A. H.: Noncoordinate regulation of de novo synthesis of cytochrome $P-450$ cholesterol side-chain cleavage and cytochrome $P-450_{17 a}$-hydroxylase $/ \mathrm{C}_{17-20}$ lyase in mouse Leydig cell cultures: relation to steroid production. Molec. Endocr. 1 (1987) 595-603 
3. Hales D. B., Sha L. and Payne A. H.: Testosterone inhibits cAMP-induced de novo synthesis of Leydig cell cytochrome $P-450_{17 \pi}$ by an androgen receptormediated mechanism. J. Biol. Chem. 262 (1987) 11200-11206.

4. Hales D. B. and Payne A. H.: Glucocorticoid-mediated repression of $P 450_{s c c} \mathrm{mRNA}$ and de novo synthesis in cultured Leydig cells. Endocrinology 124 (1989) 2099-2104.

5. Hales D. B., Sha L. and Payne A. H.: Glucocorticoid and cyclic adenosine $3^{\prime} 5^{\prime}$-monophosphate-mediated induction of cholesterol side-chain cleavage cytochrome $P 450\left(P 450^{\circ c}\right)$ in MA-10 tumor Leydig cells. Increases in mRNA are cycloheximide sensitive. Endocrinology 126 (1990) 2800-2808.

6. Evain D., Morera A. M. and Saez J. M.: Glucocorticoid receptors in interstitial cells of the rat testis. J. Steroid Biochem. 7 (1976) 1135-1139.

7. Griffin J. E. and Wilson J. D.: Disorders of the testes and male reproductive tract. In Williams Textbook of Endocrinology (Edited by J. D. Wilson and D. W. Foster). Edn 7 (1985) 284.

8. Payne A. H. and Sha L.: Multiple mechanisms for regulation of $3 \beta$-hydroxysteroid dehydrogenase/ $\Delta^{5}$ - $\Delta^{4}$-isomerase, $17 \alpha$-hydroxylase $/ C_{17-20}$ lyase cytochrome $P 450$, and cholesterol side-chain cleavage cytochrome $P 450$ mRNA levels in primary cultures of mouse Leydig cells. Endocrinology 129 (1991) 1429-1435.

9. Roesler W. J., Vandenbark G. R. and Hanson R. W.: Cyclic AMP and the induction of eukaryotic gene transcription. J. Biol. Chem. 263 (1988) 9063-9066.

10. John M. E., John M. C., Boggaram V., Simpson E. R. and Waterman M. R.: Transcriptional regulation of steroid hydroxylase genes by ACTH. Proc. Natn. Acad. Sci. U.S.A. 83 (1986) 4715-4719.

11. Zuber M. X., John M. E., Okamura T., Simpson E. R. and Waterman M. R.: Bovine adrenocortical cytochrome $P 450_{17 \alpha}$. Regulation of gene expression by ACTH and elucidation of primary sequence. J. Biol. Chem. 261 (1986) 2474-2482.

12. Ahlgren R., Simpson E. R., Waterman M. R. and Lund $\mathrm{J} .:$ Characterization of the promoter/regulatory region of the bovine CYP11A $\left(P 450_{s c c}\right)$ gene. Basal and cAMPdependent expression. J. Biol. Chem. 265 (1990) 3313-3319.

13. Lund J., Ahlgren R., Wu D., Kagimoto M., Simpson E. R. and Waterman M. R.: Transcriptional regulation of the bovine CYP17 $\left(P_{450_{17 a}}\right)$ gene. Identification of two cAMP regulatory regions lacking the consensus cAMP-responsive element (CRE). J. Biol. Chem. 265 (1990) 3304-3312.

14. Picado-Leonard J., Voutilainen R., Kaol Chung B., Strauss III J. F. and Miller W. L.: Human adrenodoxin: cloning of three cDNAs and cycloheximide enhancement in JEG-3 cells. J. Biol. Chem. 263 (1988) 3240-3244.

15. Golos T. G., Miller W. L. and Strauss III J. F.: Human chorionic gonadotropin and 8-bromo cyclic adenosine monophosphate promote an acute increase in cytochrome $\mathbf{P 4 5 0}_{\mathrm{scc}}$ and adrenodoxin messenger RNAs in cultured human granulosa cells by a cycloheximideinsensitive mechanism. J. Clin. Invest. 80 (1987) 896-899.
16. Hales D. B., Sha L. and Payne A. H.: Glucocorticoid and cyclic adenosine $3^{\prime} 5^{\prime}$-monophosphate-mediated induction of cholesterol side chain cleavage cytochrome $P 450\left(P_{450}\right)$ in MA-10 Leydig cells: increases in mRNA are cycloheximide sensitive. Endocrinology 26 (1990) 2800-2808.

17. Mellon S. H. and Vaisse C.: cAMP regulates $\mathbf{P} 450^{300}$ gene expression by a cycloheximide-insensitive mechanism in cultured mouse Leydig MA-10 cells. Proc. Natn. Acad. Sci. U.S.A. 86 (1989) 7775-7779.

18. Youngblood G. L. and Payne A. H.: Molec. Endocr. (1992) In press.

19. Ascoli M.: Characterization of several clonal lines of cultured Leydig tumor cells gonadotropin receptors and steroidogenic responses. Endocrinology 108 (1981) 88-95.

20. Picado-Leonard J. and Miller W. L.: Cloning and sequencing of the human gene for $\mathrm{P}^{4} \mathrm{CO}_{\mathrm{cl}}$ (steroid $17 \alpha$-hydroxylase/17,20 lyase): similarly with the gene for $\mathrm{P}_{450} \mathrm{c21}$. DNA 6 (1987) 439-448.

21. Bhasker R. C., Adler B. S., Dee A., John M. E., Kagimoto M., Zuber M. X., Ahlgren R., Wang X., Simpson E. R. and Waterman M. R.: Structural characterization of the bovine CYP17 (17 $\alpha$-hydroxylase) gene. Archs Biochem. Biophys. 271 (1989) 479-487.

22. Brentano S. T., Picado-Leonard J., Mellon S. H., Moore C. C. D. and Miller W. L.: Tissue-specific, cyclic adenosine $3^{\prime}, 5^{\prime}$-monophosphate-induced, and phorbol ester-repressed transcription from the human $P 450_{\mathrm{cl}}$ ? promoter in mouse cells. Molec. Endocr. 4 (1990) 1972-1979.

23. Adler J. A., Shellar A., Hoffman Y. and Robins D. M.: Multiple components of a complex androgen-dependent enhancer. Molec. Endocr. 5 (1991) 1587-1596.

24. He W. W., Fischer L. M., Sun S., Bilhartz D. L., Zhu X., Young C. Y. F., Kelley D. B. and Tindall D. J.: Molecular cloning of androgen receptors from divergent species with a polymerase chain reaction technique: complete cDNA sequence of the mouse androgen receptor and isolation of androgen receptor cDNA probes from dog, guinea pig and clawed frog. Biochem. Biophys. Res. Commun. 171 (1990) 697-704.

25. van Laar J. H., Berrevoets C. A., Trapman J., Zegers N. D. and Brinkman A. O.: Hormone-dependent androgen receptor phosphorylation is accompanied by receptor transformation in human lymph node carcinoma of prostrate cells. J. Biol. Chem. 266 (1991) 3734-3738.

26. Denner L. A., Weigel N. L., Maxwell B. T., Schrader W. T. and O'Malley B. W.: Regulation of progesterone receptor-mediated transcription by phosphorylation. Science 250 (1990) 1740-1743.

27. Rice D. A., Kirkman M. S., Aitken L. D., Mouw A. R., Schimmer B. P. and Parker K. L.: Analysis of the promoter region of the gene encoding mouse cholesterol side-chain cleavage enzyme. J. Biol. Chem. 265 (1990) 11713-11720.

28. Perkins L. M. and Payne A. H.: Quantification of $P 450_{\text {scc }}, P \mathbf{4 5 0}_{17 \alpha}$ and iron sulfur protein reductase in Leydig cells and adrenals of inbred strains of mice. Endocrinology 123 (1988) 2675-2682.

29. Nolan C. J. and Payne A. H.: Genotype at the $P 450_{\text {soc }}$ locus determines differences in the amount of $P 450_{s 0 x}$ protein and maximal testosterone production in mouse Leydig cells. Molec. Endocr. 4 (1990) 1459-1464. 